\title{
Validation of Quantitative Magnetic Resonance Body Composition Analysis for Infants Using Piglet Model
}

\author{
ALVA D. MITCHELL
}

Animal Bioscience and Biotechnology Laboratory, USDA-ARS, Beltsville, Maryland 20715

\begin{abstract}
A study was conducted to validate the use of a quantitative magnetic resonance (QMR) device for measuring the body composition of infants and neonates weighing $<12 \mathrm{~kg}$ using the pig as a model. A total of 25 piglets weighing between 2 and $12 \mathrm{~kg}$ were studied. Body composition was assessed by QMR, dual-energy X-ray absorptiometry (DXA), and whole-body chemical analysis (CA) of carcass for lipid and water content. The precision, mean and SD of repeated measurements, of QMR to estimate fat mass (FM), lean mass (LM), and total body water (TBW) for five consecutive scans with reposition was $12.5,32.0$, and $36.0 \mathrm{~g}$, respectively. QMR measures of FM, LM, and TBW were highly and significantly correlated with CA of carcass. In terms of accuracy, mean difference between QMR and CA (percent of mean value for CA), QMR overestimated FM by $40 \mathrm{~g}(4.7 \%)$, overestimated LM by $114.9 \mathrm{~g}$ (2.1\%), and underestimated TBW by $134.6 \mathrm{~g}$ (3.1\%). This study concludes that QMR provides precise and accurate measures of FM, $\mathrm{LM}$, and TBW in piglet weighing up to $12 \mathrm{~kg}$. These results suggest that QMR can provide valuable body composition data in longitudinal studies in infants. (Pediatr Res 69: 330-335, 2011)
\end{abstract}

$\mathrm{A}^{\mathrm{c}}$ ccurate assessment and tracking of infant body composition is useful in evaluating the amount and quality of weight gain, which can provide key information in both clinical and research settings. Body composition analysis (BCA) can be used to monitor and evaluate infant growth patterns, efficacy of nutritional and medical interventions, progression of chronic disease, and recovery from malnutrition (1-5).

A large variety of nondestructive BCA methods have been developed, each with its advantages and shortcomings, such as air-displacement plethysmography (ADP) (6), bioelectrical impedance analysis (BIA) (7), dual-energy x-ray absorptiometry (DXA) (8), total-body electrical conductivity (TOBEC) (9), total body potassium (TBK) (10), isotope dilution (11), skin-fold thickness measurements (SFT) (12), multicompartment models (13), computed tomography (CT) (14), MRI (15), magnetic resonance spectroscopy (MRS) (16), and quantitative magnetic resonance (QMR) (17).

Received July 12, 2010; accepted October 22, 2010

Correspondence: Alva D. Mitchell, Ph.D., Animal Bioscience and Biotechnology Laboratory, USDA-ARS, 10300 Baltimore Avenue, Beltsville, MD 20715; e-mail: alva.mitchell@ars.usda.gov

Supported by Grant R43DK079395 from the NIDDK.

The content is solely the responsibility of the authors and does not necessarily represent the official views of the NIDDK or the NIH. Mention of a trade name does not constitute a guarantee or warranty by the USDA and does not imply its approval to the exclusion of other products that may be suitable.
Common shortcomings include complexity and time needed to obtain results (multicomponent models, TBK, isotope dilution, MRI, and MRS), immobilization requirement (MRI, MRS, CT, and DXA), expensive equipment (MRI, MRS, CT, DXA, QMR, and TOBEC), reliability and correspondence of relations between measured quantities and body components (BIA, TOBEC, ADP, and SFT), radiation exposure (CT and DXA), and potential vulnerability to oversimplification (ADP and SFT).

QMR devices stand out in that they are fast and very easy to use, require no sedation or anesthesia, and are free of radiation, while capable of unsurpassed precision and high accuracy. Typical scan times range from $<1 \mathrm{~min}$ to $<4 \mathrm{~min}$ in different specific devices and applications, and less than half an hour of training is sufficient for a typical user.

The QMR method is a branch of nuclear magnetic resonance (NMR), for whole body measurement of fat, lean tissues, free water (not bound in various tissues), and total body water (TBW, water contained in all the liquids and in tissues) of live animals including humans. QMR differs from MRI in that the processed signal is obtained from the whole body at once (without spatial encoding) and it differs from MRS in that the time domain signal (rather than spectrum) is processed directly. Principles of QMR are described elsewhere (17-22). Briefly, this system generates a signal that modifies the spin patterns of hydrogen atoms within the subject and uses an algorithm to evaluate the resulting $\mathrm{T} 1$ and $\mathrm{T} 2$ relaxation curves specific to each of the four components measured: fat mass (FM), lean muscle mass equivalent, TBW, and free water. Each component is estimated based on an individually derived T1/T2 relaxation curve fractionated from the total returned signal.

Success in using QMR in animals of different sizes (flies, mice, rats, birds, dogs, pigs, infants, children, and adult humans) has been comprehensively reported (17-22). This study addresses its potential for infants, using piglets as a generally accepted research model for infant body composition $(23,24)$. 
There have been many studies of pig BCA, in particular, comparing DXA with chemical analysis (CA) (25-27) and comparing DXA with tissue dissection (28). This study validates, at the same time, QMR and DXA precision and accuracy using $\mathrm{CA}$ as the reference $\mathrm{BCA}$ method.

In comparative studies, QMR was found to have higher precision than all the other methods considered in these studies (17-22). The ability of QMR to precisely detect minute longitudinal differences in body composition is particularly valuable. When measuring the FM in rats (21), the coefficient of variance (CV) \% for QMR was 0.94 compared with 5.12 for CA; in mice (19), it was 1.58 for QMR compared with 2.2 for DXA; and in pigs (20), it was 1.3 for QMR compared with 3.7 for DXA.

DXA and CT can sometimes achieve repeatability comparable with that of QMR; however, these BCA methods require immobilization and various degree of $\mathrm{x}$-ray irradiation, both undesirable in most applications and unacceptable in applications to infants. As DXA is the closest BCA method to QMR in terms of precision, speed, and convenience of use, this validation study of QMR usually includes some comparison with DXA (17-22). This study follows that tradition and, in addition, examines by regression analysis the corrections that are usually needed for DXA and can be used in the same way for QMR. This validation study was a part of more extensive study which will be fully described in the future. Future studies will include the use of QMR to evaluate the changes in body composition during growth of both the piglet and the human infant.

\section{MATERIALS AND METHODS}

Animals and procedures. Twenty-five piglets weighing $<12 \mathrm{~kg}$ were used to validate the QMR device. Each piglet was scanned by QMR (EchoMRIInfants) five times and by DXA (Lunar Prodigy) three times while anesthetized and then subjected to CA. As DXA requires anesthesia, for better comparability, piglets were anesthetized for QMR as well. The calibration of both the QMR and the DXA was checked each day immediately before scanning. All devices were installed at USDA Animal Bioscience and Biotechnology Laboratory, Beltsville, MD.

The piglets were sedated using an intramuscular injection of a mixture of ketamine, Telazol (tiletamine + zolazepam), and xylazine (5.0 $\mathrm{mg}$ ketamine, $0.8 \mathrm{mg}$ tiletamine, $0.8 \mathrm{mg}$ zolazepam, and $3.3 \mathrm{mg}$ xylazine per $\mathrm{kg}$ body weight). While still sedated, the piglets were killed by an intracardiac injection of pentobarbital. Immediately after scanning, the piglet carcass was sealed in a plastic bag and frozen at $-15^{\circ} \mathrm{C}$ until processing for CA.

All QMR scans, DXA scans, and carcass analysis for all the piglets was performed by the same person. Experimental protocols used in this study were approved by the Beltsville Area Institutional Animal Care and Use Committee.
BCA methods. QMR EchoMRI-Infants (Echo Medical Systems, Houston, TX) device was used for subjects weighing up to $12 \mathrm{~kg}$. The device weight is $\sim 1000 \mathrm{~kg}$ and has external dimensions of $L \times W \times H$ is $120 \times 60 \times 180 \mathrm{~cm}^{3}$. The resistive magnet generates a static magnetic field of $\sim 0.0145$ Tesla in a bore size of $L \times W \times H$ is $120 \times 30 \times 30 \mathrm{~cm}^{3}$. The field of view is a $25-\mathrm{cm}$ diameter, $60-\mathrm{cm}$ long cylinder in the center of the bore and the system is self-shielded. The operating system is based on Windows XP Professional Edition. Measuring time is typically $<3 \mathrm{~min}$, with three repeat measurements taking $<10 \mathrm{~min}$; there is a recommended daily system test in the most recent software. The system output includes FM, lean tissue mass, free water, and total water in units of grams.

DXA Lunar Prodigy (GE Lunar, Madison, WI) device was tested as supplied by manufacturer. Details of piglet measurement by DXA are described elsewhere (29). Scans were performed and analyzed using the Small Animal Mode (version 8.10). The quantities measured by DXA are FM, lean mass (LM), and bone mineral content (BMC).

Chemical analysis. For CA, the entire body was homogenized, and then samples were analyzed for total water and lipid (fat) content. Lipid content was measured by chloroform/methanol extraction (30) and water content was measured by lyophilization. The quantities measured by CA are FM and TBW. Particular details are the following.

Carcass preparation. Piglets weighing $>5 \mathrm{~kg}$ were homogenized three times using a whole-body grinder (Autio Model $810 \mathrm{M} \mathrm{GH}$, Astoria, OR). Piglets weighing $\leq 5 \mathrm{~kg}$ were autoclaved for $2 \mathrm{~h}$ at $121^{\circ} \mathrm{C}$, cooled to $3^{\circ} \mathrm{C}$, and then homogenized for $1 \mathrm{~min}$ using a food processor (Robot Coupe, Model $\mathrm{R} 10$, Jackson, MS). Samples were stored at $-15^{\circ} \mathrm{C}$ before analysis.

Water analysis. A single sample from each piglet was weighed (sample size was $\sim 400 \mathrm{~g}$ ), frozen, and then lyophilized in a freeze dryer (Virtis, Model 100 SRC-6, Gardiner, NY) for $14 \mathrm{~d}$. The samples were weighed again immediately after removal from freeze dryer, and the weight difference between the two weightings was assumed to be due to water loss.

Lipid analysis. Quadruplicate 3 to $5 \mathrm{~g}$ samples of the wet homogenate were extracted for lipid analysis by the method of chloroform/methanol extraction (30). Each sample was extracted for $24 \mathrm{~h}$ in a $125-\mathrm{mL}$ separatory funnel containing $60 \mathrm{~mL}$ of chloroform:methanol (2:1, vol/vol). After $24 \mathrm{~h}, 12$ $\mathrm{mL}$ of $0.88 \%$ potassium chloride in water was added and then mixed by shaking for $10 \mathrm{~s}$. The sample was allowed to set for another $24 \mathrm{~h}$ to permit phase separation. The lower phase was then drained into preweighed vials and the solvent evaporated off at $70^{\circ} \mathrm{C}$ under a stream of nitrogen in a sample concentrator (Sybron SC248 Sample Concentrator, Brinkman Instruments, Canada). The vials were allowed to cool and then reweighed to determine the amount of lipid extracted.

Calculations and statistics. Statistics were done using custom software. The results of QMR, DXA, and CA analysis were correlated, and precision and accuracy were evaluated.

Validity was evaluated by comparing the QMR variables with chemical carcass analysis variables by paired $t$ tests, and linear regression analysis to determine whether the results passed through the origin and had a slope that did not differ from unity. In addition, the root mean square error (RMSE) for each equation was calculated to assess performance. For regression analysis, the mean absolute error (MAE) was calculated as the average value of the residuals. The measurement of fat content by QMR was also compared with that by CA by plotting the difference between the two measurements against the average of the two measurements (Bland-Altman plot) (31).

\section{RESULTS}

The mean values for the measurement of total body fat, lean, and water by QMR, DXA, and CA are shown in Table

Table 1. Mean [plusmn] SD values for measurement of body composition components by CA, QMR, and DXA

\begin{tabular}{|c|c|c|c|c|c|c|}
\hline \multirow{2}{*}{$\begin{array}{l}\text { Body composition } \\
\text { component }\end{array}$} & \multicolumn{2}{|c|}{$\mathrm{CA}$} & \multicolumn{2}{|c|}{ QMR } & \multicolumn{2}{|c|}{ DXA } \\
\hline & Mean \pm SD & Range & Mean \pm SD & Range & Mean $\pm \mathrm{SD}$ & Range \\
\hline Fat $(\mathrm{g})$ & $854 \pm 428$ & $95-1447$ & $894 \pm 448^{*}$ & $123-1557$ & $1034 \pm 515^{*}$ & $162-1724$ \\
\hline Fat $(\%)$ & $12.6 \pm 3.3$ & $4.8-17.1$ & $13.2 \pm 3.3 *$ & $6.2-17.9$ & $15.6 \pm 4.4^{*}$ & $8.3-22.6$ \\
\hline Lean $(\mathrm{g})$ & $5391 \pm 2099 \ddagger$ & 1482-9032 & $5506 \pm 2135$ & $1956-9359$ & $5130 \pm 2050$ & $1767-8927$ \\
\hline Water (g) & $4395 \pm 1730$ & $1486-7343$ & $4257 \pm 1593 \neq$ & $1485-7016$ & & \\
\hline
\end{tabular}

QMR and DXA values were compared with CA by paired $t$ test.

$* p<0.001$.

$\dagger \mathrm{CA}$ lean $=\mathrm{BWT}-(\mathrm{CA}$ fat + DXA BMC $)$.

$\ddagger p<0.01$. 
1. Compared with CA, both QMR and DXA significantly overestimated total body fat, QMR by $4.7 \%$ and DXA by $21 \%$. The RMSE for the prediction of FM by QMR was calculated as $65 \mathrm{~g}$, and the RMSE by DXA was $215 \mathrm{~g}$.

Although not significant, the QMR measurement of total body lean was $2.1 \%$ less than CA while DXA was $4.8 \%$ less. The QMR measurement of TBW was only $3.1 \%$ less that the CA measurement, yet significantly lower based on the paired $t$ test $(p<0.05)$. The differences between the measurements by QMR and DXA and those by CA, including the RMSE, are shown in Table 2.

The relationship between the CA for total body fat, lean, and water and the measurements obtained by QMR and DXA are shown in Figures 1-3. In all cases, there results were highly correlated. For both fat and lean, the slope of the regression line was closer to 1.0 with QMR than with DXA. By regression analysis, the mean absolute error for the prediction FM was $30 \mathrm{~g}$ for QMR and $54 \mathrm{~g}$ for DXA. For the prediction of LM, the mean absolute error was $123 \mathrm{~g}$ for QMR and $108 \mathrm{~g}$ for DXA.

Precision of fat/QMR in terms of SD ranged from 4.15 to $24.47 \mathrm{~g}$ with a mean and $\mathrm{SD}$ of $11.67 \pm 5.19 \mathrm{~g}$, resulting in mean CV of $1.31 \%$. Precision of lean/QMR, TBW/QMR, fat/DXA, and lean/DXA in terms of SD are presented in Table 3. A plot of the SD for repeatability measurement of FM for each piglet measured by QMR relative to the body weight of the pig is shown in Figure 4. The relationship between precision of fat/QMR in terms of $\mathrm{CV}$ ranged from 0.44 to $8.61 \%$, with a mean and SD of $1.80 \pm 1.86 \%$. Precision of lean/QMR, TBW/QMR, fat/DXA, and lean/DXA in terms of CV are presented in Table 4. A plot of the CV for repeatability measurement of FM for each piglet measured by QMR relative to the body weight of the pig is shown in Figure 5. In Figure 6, the difference between the percentage of fat measured by QMR and CA is plotted against the average of the percentage of fat for the two methods (Bland-Altman plot). The relationship between the amount of total body fat measured by QMR and the body weight of the piglet is shown in Figure 7.

\section{DISCUSSION}

In studies designed to validate the use of various approaches for measuring human body composition, a variety of reference methods have been used, and in many cases, more than one. DXA has been used extensively in studies of both infant and adult human body composition and is frequently

Table 2. Accuracy of measuring body composition by $Q M R$ and DXA with reference to chemical analysis

\begin{tabular}{|c|c|c|c|c|c|}
\hline \multirow[b]{2}{*}{ Measuring method } & \multicolumn{3}{|c|}{ QMR } & \multicolumn{2}{|c|}{ DXA } \\
\hline & Fat & Lean & TBW & Fat & Lean \\
\hline \multicolumn{6}{|l|}{$\begin{array}{l}\text { Body composition } \\
\text { component }\end{array}$} \\
\hline Average difference $(\mathrm{g})$ & 40 & 115 & -138 & 180 & -261 \\
\hline $\begin{array}{c}\text { Average difference as } \\
\% \text { of average CA }\end{array}$ & 4.7 & 2.1 & -3.1 & 21.1 & -4.8 \\
\hline RMSE (g) & 67.7 & 204.0 & 274.5 & 224.5 & 306.5 \\
\hline
\end{tabular}

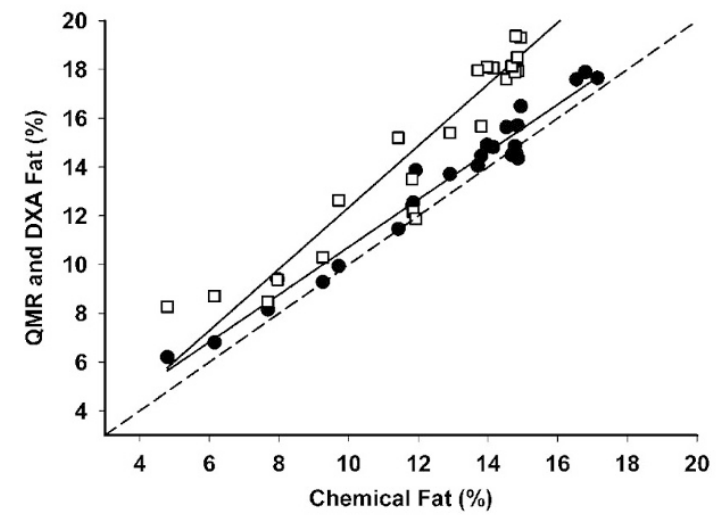

Figure 1. Total body FM measured by QMR ( ) and DXA ( $\square$ ) vs. CA of carcass for piglets weighing $<12 \mathrm{~kg}$. QMR, $Y=6.75+1.040 X, R^{2}=0.988$; DXA, $Y=20.73+1.186 X, R^{2}=0.968 ;---$ indicates line of identity.

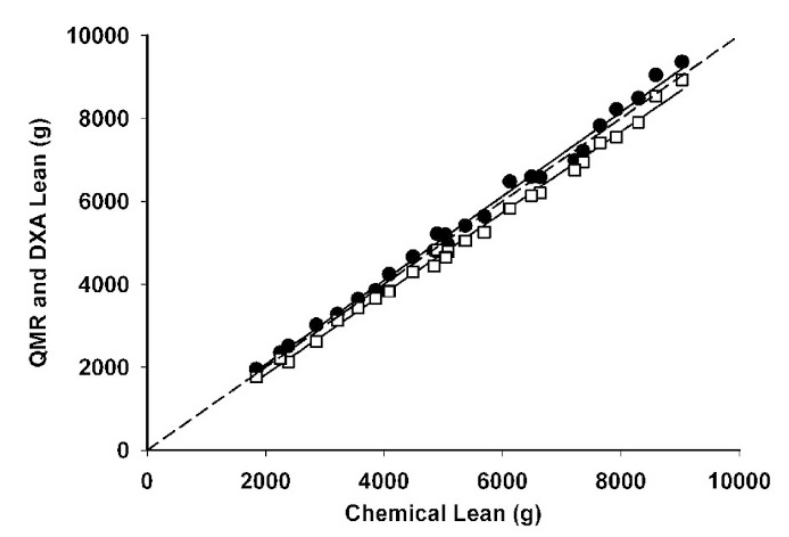

Figure 2. Total body LM measured by QMR $(\bullet)$ and DXA $(\square) v s$. CA of carcass for piglets weighting $<12 \mathrm{~kg}$. QMR, $Y=31.7+1.015 X, R^{2}=0.994$; DXA, $Y=-126+0.975 X, R^{2}=0.996 ;---$ indicates line of identity.

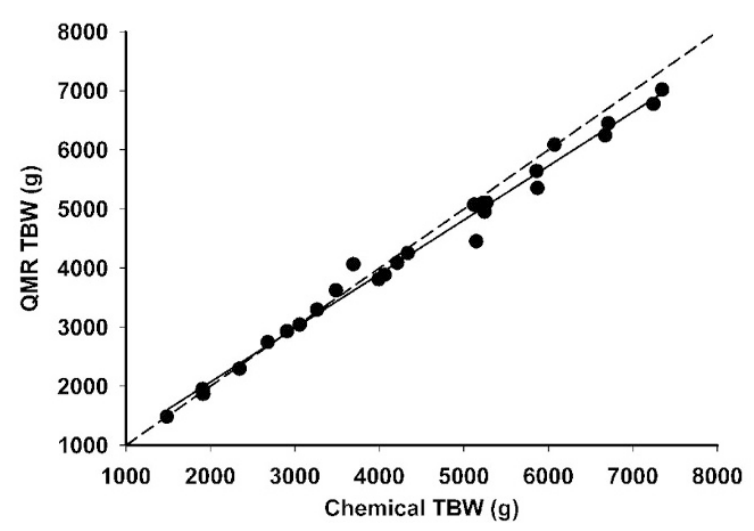

Figure 3. TBW measured by QMR (๑) vs. CA of carcass for piglets weighting $<12 \mathrm{~kg}$. QMR, $Y=238+0.915 X, R^{2}=0.988 ;---$ indicates line of identity.

used as a reference method for validating other methods. However, the most recognized reference BCA method for animals is CA (30). This study compares QMR to both CA and DXA, thus evaluating it relative to a well-defined reference method and to a method that is commonly used in human studies.

Although QMR measurement does not require anesthesia, all piglets were measured in the anesthetized state as required 
Table 3. Precision of measuring body composition by $Q M R$ and $D X A$ in terms of $S D$ in units of grams

\begin{tabular}{lrrrrrr}
\hline \multirow{2}{*}{$\begin{array}{c}\text { Measuring } \\
\text { method }\end{array}$} & \multicolumn{3}{c}{ QMR } & & \multicolumn{2}{c}{ DXA } \\
\cline { 3 - 4 } \cline { 6 - 7 } $\begin{array}{c}\text { Fody composition } \\
\text { component }\end{array}$ & & Lean & TBW & & Fat & Lean \\
\hline Mean (SD) g & 11.67 & 29.61 & 29.09 & & 27.08 & 27.38 \\
SD (SD) g & 5.19 & 14.76 & 29.07 & & 14.93 & 15.03 \\
Range (min) g & 4.15 & 8.11 & 6.77 & & 6.11 & 5.16 \\
Range (max) g & 24.47 & 66.19 & 157.98 & & 58.03 & 57.80 \\
\hline
\end{tabular}

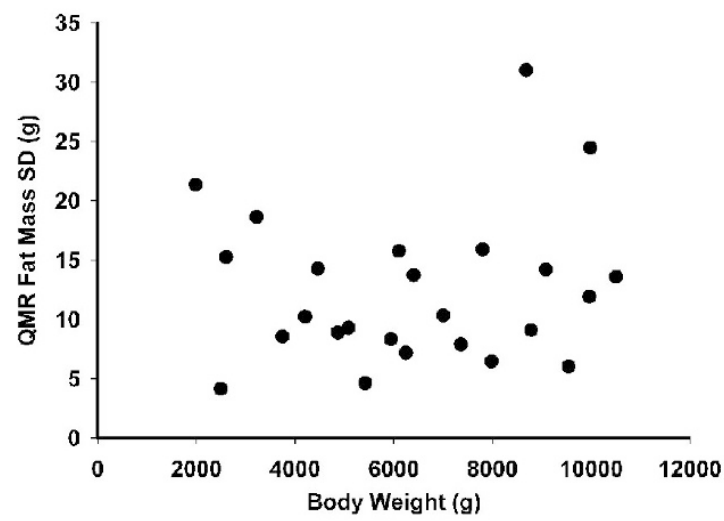

Figure 4. Standard deviation for repeatability measurement of FM for each piglet measured by QMR as a function of body weight.

Table 4. Precision of measuring body composition by QMR and DXA in terms of CV units of \%

\begin{tabular}{lllllll}
\hline & \multicolumn{3}{c}{ QMR } & & \multicolumn{2}{c}{ DXA } \\
\cline { 2 - 4 } Measuring method & Fat & Lean & TBW & & Fat & Lean \\
\hline $\begin{array}{c}\text { Body composition } \\
\quad \text { component }\end{array}$ & & & & & \\
Mean CV \% & 1.80 & 0.60 & 0.85 & & 3.09 & 0.56 \\
SD (CV) \% & 1.86 & 0.39 & 1.12 & & 1.98 & 0.32 \\
Range (min) \% & 0.44 & 0.12 & 0.13 & & 0.71 & 0.18 \\
Range (max) \% & 8.61 & 1.66 & 5.75 & 8.12 & 1.35 \\
\hline
\end{tabular}

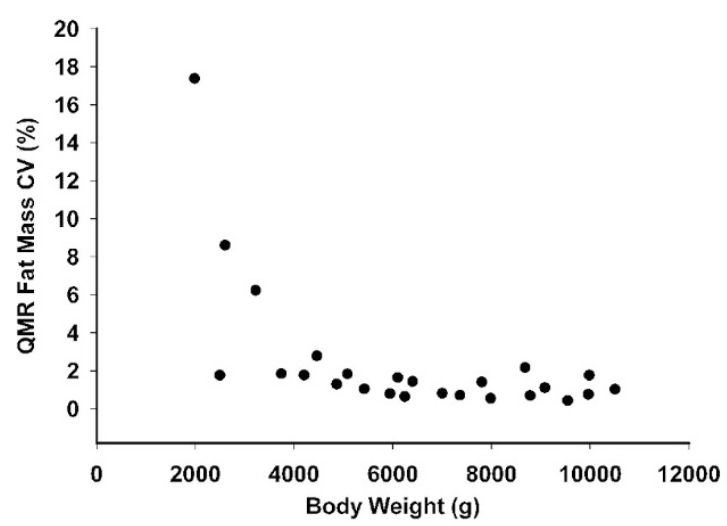

Figure 5. CV for repeatability measurement of FM for each piglet measured by QMR as a function of body weight.

by DXA so that conditions would be the same for both measurements. In addition, by 4 or $5 \mathrm{~d}$ after birth, the newborn piglet is quite robust and its level of activity, even if confined or restrained, would be far greater than would be observed with the human infant, thus the anesthetized piglet would be a

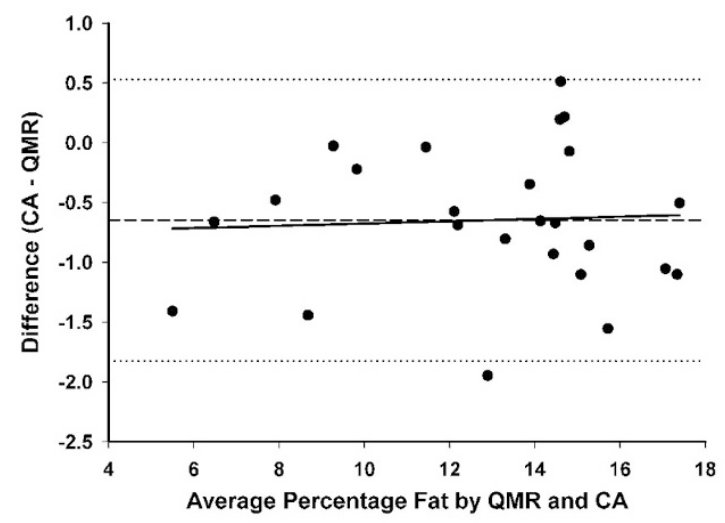

Figure 6. Bland-Altman plot comparing the average percentage of fat measured by QMR and CA to the difference in the values (CA-QMR) for the two methods. ---, mean difference; $\cdots \cdots$, mean $\pm 2 \mathrm{SD} ;-$, regression line.

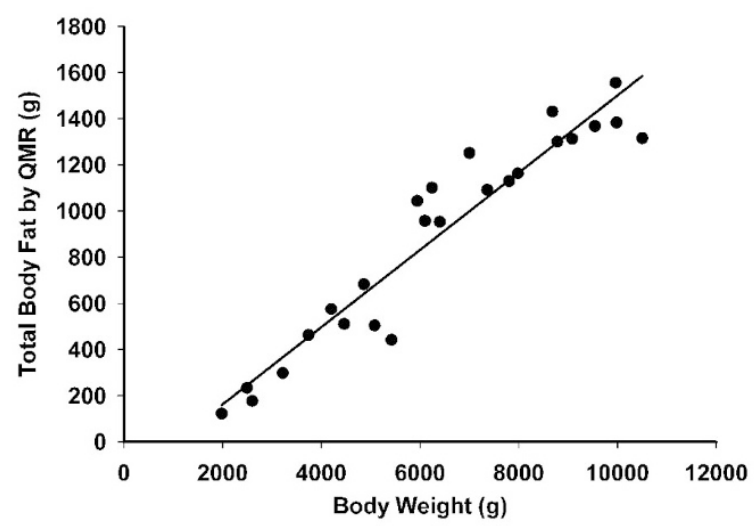

Figure 7. Relationship between FM measurement and body weight. $R^{2}=0.91$.

better model for the human infant. It was observed and reported elsewhere that precision for measuring anesthetized piglets by QMR is about twice better than for nonanesthetized. One of five repeats of QMR measurements for one of 25 animals ( 1 of 125 scans) was found to be outlier and was excluded from further analysis. One of three repeats of DXA measurements for one of 25 animals ( 1 of 75 scans) was found to be outlier and was excluded from further analysis. The Bland-Altman plot (Fig. 6) shows that compared with CA, QMR overestimated the percentage of total body fat in piglets by $0.6 \%$. There is little or no indication of a trend for the difference between the methods to increase as the average increases (regression slope $=0.009$ ). Furthermore, it does not appear that the scatter around the bias line increases as the average gets higher.

The amount of fat was highly dependent on body weight (Fig. 7). By CA, the total body fat content of the pigs used in this study ranged from 95 to $1447 \mathrm{~g}$, compared with 123 to $1557 \mathrm{~g}$ by QMR and 162 to $1724 \mathrm{~g}$ by DXA. On average, QMR overestimated FM by $40 \mathrm{~g}$ compared with an overestimation of $180 \mathrm{~g}$ by DXA. The RMSE for the prediction equation for FM was calculated as 67.7 $\mathrm{g}$ for QMR and 224.5 $\mathrm{g}$ for DXA. Not only was the QMR measurement of total body fat closer to the CA measurement than was DXA, but also the slope of the regression line for QMR fat was closer to unity (Fig. 1). The greater accuracy of QMR for measuring fat 
content of piglets compared with DXA is in agreement with a recent study that reported that QMR overestimated FM by 2\%, compared with $15 \%$ by DXA (20). QMR showed excellent precision for measuring FM, with a mean CV of $1.8 \%$ compared with $3.1 \%$ for DXA. This too is in close agreement with a recent study that reported $\mathrm{CV} \sim 1.5 \%$ for $\mathrm{QMR}$ and $\mathrm{CV}$ $\sim 3.5 \%$ for DXA measurements of total body fat in pigs weighing between 3 and $50 \mathrm{~kg}$ (20). As can be seen from Figure 5, CV is a function of body weight-at low weight $(<4$ $\mathrm{kg}$ ), there was a higher $\mathrm{CV}$ compared with high weight animal. In a previous study using QMR to measure the body composition of mice (19), it was reported that there was a significant relationship between the weight of the animal and the fat $\mathrm{CV} \%$. It is not certain that this is entirely a function of body weight. At least in this study, fat content itself was also a function of body weight, as shown in Figure 7. In fact, the relationship with $\mathrm{CV} \%$ shown in Figure 5 is quite similar if $\mathrm{BF} \%$ is substituted for body weight.

The accuracy of the prediction of total body lean is somewhat arbitrary since the CA did not directly measure LM. Instead, the chemical LM was defined as: chemical lean = BWT - (fat/CA + BMC/DXA), where BWT is the live body weight. Using this reference, the accuracy and precision for the prediction of LM was similar for QMR and DXA. The RMSE for the prediction equation for total body lean was calculated as $204 \mathrm{~g}$ for QMR and $306.5 \mathrm{~g}$ for DXA. As the LM is predominately water, the relationship between QMR and CA measurements of TBW provides a more direct comparison. Figures 1-3 demonstrate dependence of difference between QMR and CA on value of the parameter. This tendency is weaker for TBW. One reason for this is that sample sizes for CA are small; for FM measurement, 3-4 g sample is used; for TBW measurement, $400 \mathrm{~g}$ samples are used; then the result is multiplied by the animal weight. The precision of QMR for measuring TBW was very similar to that of LM.

Usage of SD or CV measures of spread is dictated by their usefulness and depends very much on the nature of measurement method and measured parameter. A goal of this study was to simply determine how to predict the precision for measuring, for example, fat in a piglet weighting $7 \mathrm{~kg}$. From Figure 4 , an SD of $\sim 10 \mathrm{~g}$ was observed for animals between 2 and $12 \mathrm{~kg}$; from Figure 6, the estimate for FM would be $\sim 1$ $\mathrm{kg}$; therefore, $\mathrm{CV}$ is expected to be $1 \%$. Recently, it was reported that with a smaller QMR instrument, DXA and QMR offered nearly the same accuracy, within $1 \%$ of weight in fat, while QMR had better precision, within $0.2 \%$ of weight in fat for anesthetized piglets compared with DXA's $0.5-0.6 \%$ (32). The same study noted that the characterization of random errors by $\mathrm{CV}$, especially that of fat, is not suitable for BCA, whereas absolute errors or errors relative to total body weight can be applicable. This conclusion was based on the significant correlations of $\mathrm{CV}$ with fat measurements.

ADP has been evaluated for measuring body composition of human infants $(33,34)$. When ADP was compared with deuterium $\left({ }^{2} \mathrm{H}_{2} \mathrm{O}\right)$ dilution, there was no difference in the mean percentage of BF $(20.32 \%$ BF by ADP and $20.39 \% \mathrm{BF}$ by ${ }^{2} \mathrm{H}_{2} \mathrm{O}$ ) and regression analysis gave an $R^{2}$ of 0.76 and a RMSE of 3.26 (33). Similarly, when ADP was compared with a four-compartment (4-C) model, there was no difference in the mean percentage of BF (16.9\% BF by ADP and 16.3 by 4-C) and regression analysis gave an $R^{2}$ of 0.73 and a RMSE of 3.7 (33). By the same measure, in this study, when QMR was compared with $\mathrm{CA}$, there was no difference $(p<0.05)$ in the mean percentage of $\mathrm{BF}(12.6 \% \mathrm{BF}$ by QMR and $13.2 \% \mathrm{BF}$ by $\mathrm{CA}$ ) and regression analysis gave an $R^{2}$ of 0.96 and a RMSE of 0.61 .

The results of this study indicate a strong potential for the use of the QMR method for measuring the body composition of human infant and warrant its evaluation in the clinical setting. The advantages of QMR over various other methods include accuracy, precision, insensitivity to movement, and no exposure to $\mathrm{x}$-rays. Furthermore, the QMR is designed for easy calibration that can be customized and updated as needed. The ability of QMR to accurately and precisely measure total body fat and water could be a valuable tool for monitoring changes in body composition of the infant in either the healthy or diseased state.

\section{REFERENCES}

1. Ong KK, Ahmed ML, Emmett PM, Preece MA, Dunger DB 2000 Association between postnatal catch-up growth and obesity in childhood: prospective cohort study. BMJ 320:967-971

2. Hyppönen E, Kenward MG, Virtanen SM, Piitulainen A, Virta-Autio P, Tuomilehto J, Knip M, Akerblom HK 1999 Infant feeding, early weight gain, and risk of type 1 diabetes. Childhood Diabetes in Finland (DiMe) Study Group. Diabetes Care 22:1961-1965

3. Botton J, Heude B, Maccario J, Ducimetière P, Charles MA 2008 Postnatal weight and height growth velocities at different ages between birth and $5 \mathrm{y}$ and body composition in adolescent boys and girls. Am J Clin Nutr 87:1760-1768

4. Stettler N, Kumanyika SK, Katz SH, Zemel BS, Stallings VA 2003 Rapid weight gain during infancy and obesity in young adulthood in a cohort of African Americans. Am J Clin Nutr 77:1374-1378

5. Michels KB, Willett WC, Graubard BI, Vaidya RL, Cantwell MM, Sansbury LB, Forman MR 2007 A longitudinal study of infant feeding and obesity throughout life course. Int J Obes (Lond). 31:1078-1085

6. Sainz RD, Urlando A 2003 Evaluation of a new pediatric air-displacement plethysmograph for body-composition assessment by means of chemical analysis of bovine tissue phantoms. Am J Clin Nutr 77:364-370

7. Dung NQ, Fusch G, Armbrust S, Jochum F, Fusch C 2007 Body composition of preterm infants measured during the first months of life: bioelectrical impedance provides insignificant additional information compared to anthropometry alone. Eur J Pediatr 166:215-222

8. Shypailo RJ, Butte NF, Ellis KJ 2008 DXA: can it be used as a criterion reference for body fat measurements in children? Obesity (Silver Spring) 16:457-462

9. de Bruin NC, van Velthoven KA, Stunen T, Juttman RE, Degenhart HJ, Visser HK 1995 Quantitative assessment of infant body fat by anthropometry and total body electrical conductivity. Am J Clin Nutr 61:279-286

10. Butte NF, Hopkinson JM, William WW, O'Brian Smith E, Ellis KJ 2000 Body composition during the first 2 years of life: An updated reference. Pediatr Res 47:578-585

11. Wong WW, Lee LS, Klein PD 1987 Deuterium and oxygen-18 measurements on microliter samples of urine, plasma, saliva, and human milk. Am J Clin Nutr 45:905-913

12. Schmelzle HR, Fusch C 2002 Body fat in neonates and young infants: validation of skinfold thickness versus dual-energy X-ray absorptiometry. Am J Clin Nutr 76:1096-1100

13. Fomon SJ, Haschke F, Ziegler EE, Nelson SE 1982 Body composition of reference children from birth to age 10 years. Am J Clin Nutr 35:1169-1175

14. McEvoy FJ, Madsen MT, Nielsen MB, Svalastoga EL 2009 Computer tomographic investigation of subcutaneous adipose tissue as an indicator of body composition. Acta Vet Scand 51:28

15. Ibáñez L, Lopez-Bermejo A, Suárez L, Marcos MV, Díaz M, de Zegher F 2008 Visceral adiposity without overweight in children born small for gestational age. J Clin Endocrinol Metab 93:2079-2083

16. Mitchell AD, Elsasser TH, Wang PC 1991 Determination of fat and water content in vitro and in vivo by proton magnetic resonance spectroscopy. J Sci Food Agric 56:265-276

17. Taicher GZ, Tinsley FC, Reiderman A, Heiman ML 2003 Quantitative magnetic resonance (QMR) method for bone and whole-body-composition analysis. Anal Bioanal Chem 377:990-1002

18. Tinsley FC, Taicher GZ, Heiman ML 2004 Evaluation of a quantitative magnetic resonance method for mouse whole body composition analysis. Obes Res 12:150160 
19. Jones AS, Johnson MS, Nagy TR 2009 Validation of quantitative magnetic resonance for the determination of body composition of mice. Int J Body Compos Res 7:67-72

20. Andres A, Mitchell AD, Badger TM 2010 QMR:validation of an infant and children body composition instrument using piglets against chemical analysis. Int $\mathrm{J}$ Obes (Lond). 34:775-780

21. Nixon JP, Zhang M, Wang C, Kuskowski MA, Novak CM, Levine JA, Billington CJ, Kotz CM 2010 Evaluation of a quantitative magnetic resonance imaging system for whole body composition analysis in rodents. Obesity (Silver Spring) 18:16521659

22. Napolitano A, Miller SR, Murgatroyd PR, Coward WA, Wright A, Finer N, De Bruin TW, Bullmore ET, Nunez DJ 2008 Validation of a quantitative magnetic resonance method for measuring human body composition. Obesity (Silver Spring) 16:191-198

23. Brunton JA, Bayley HS, Atkinson SA 1993 Validation and application of dualenergy X-ray absorptiometry to measure bone mass and body composition in small infants. Am J Clin Nutr 58:839-845

24. Koo WW, Hammami M, Shypailo RJ, Ellis KJ 2004 Bone and body composition measurements of small subjects: discrepancies from software for fan-beam dua energy X-ray absorptiometry. J Am Coll Nutr 23:647-650

25. Mitchell AD, Scholz AM, Conway JM 1998 Body composition analysis of small pigs by dual-energy X-ray absorptiometry. J Anim Sci 76:2392-2398

26. Ellis KJ, Shypailo RJ, Pratt JA, Pond WG 1994 Accuracy of dual-energy x-ray absorptiometry for body composition measurements in children. Am J Clin Nutr 60:660-665
27. Brunton JA, Weiler HA, Atkinson SA 1997 Improvement in the accuracy of dual energy X-ray absorptiometry for whole body and regional analysis of body composition: validation using piglets and methodologic considerations in infants. Pediatr Res 41:590-596

28. Provyn S, Clarys JP, Wallace J, Scafoglieri A, Reilly T 2008 Quality control, accuracy, and prediction capacity of dual energy X-ray absorptiometry variables and data acquisition. J Physiol Anthropol 27:317-323

29. Mitchell AD, Conway JM, Scholz AM 1996 Incremental changes in total and regional body composition of growing pigs measured by dual-energy x-ray absorptiometry. Growth Dev Aging 60:95-105

30. Folch J, Lees M, Sloan-Stanley GH 1957 A simple method for the isolation and purification of total lipids from animal tissues. J Biol Chem 226:497-509

31. Bland JM, Altman DG 1986 Statistical methods for assessing agreement between two methods of clinical measurement. Lancet 327:307-310

32. Kovner I, Taicher GZ, Mitchell AD 2010 Calibration and validation of EchoMRI whole body composition analysis based on chemical analysis of piglets, in comparison with the same for DXA. Int J Body Compos Res 8:17-29

33. Ma G, Yao M, Liu Y, Lin A, Zou H, Urlando A, Wong WW, Nommsen-Rivers L, Dewey KG 2004 Validation of a new pediatric air-displacement plethysmograph for assessing body composition in infants. Am J Clin Nutr 79:653-660

34. Ellis KJ, Yao M, Shypailo RJ, Urlando A, Wong WW, Heird WC 2007 Bodycomposition assessment in infancy: air-displacement plethysmography compared with a reference 4 compartment model. Am J Clin Nutr 85:90-95 